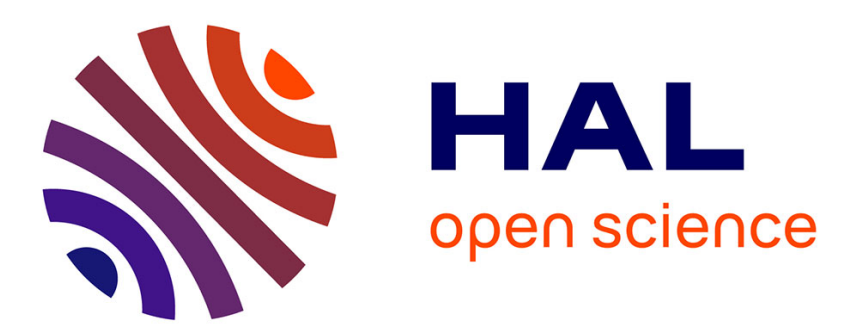

\title{
Toward a customized multicriterion tool for product evaluation in the early design phases: the CMDET methodology
}

Kévin Audoux, Frédéric Segonds, Olivier Kerbrat, Améziane Aoussat

\section{- To cite this version:}

Kévin Audoux, Frédéric Segonds, Olivier Kerbrat, Améziane Aoussat. Toward a customized multicriterion tool for product evaluation in the early design phases: the CMDET methodology. International Journal on Interactive Design and Manufacturing, 2019, 13 (3), pp.981-993. 10.1007/s12008-01900549-8 . hal-02461003

\section{HAL Id: hal-02461003 https://hal.science/hal-02461003}

Submitted on 30 Jan 2020

HAL is a multi-disciplinary open access archive for the deposit and dissemination of scientific research documents, whether they are published or not. The documents may come from teaching and research institutions in France or abroad, or from public or private research centers.
L'archive ouverte pluridisciplinaire HAL, est destinée au dépôt et à la diffusion de documents scientifiques de niveau recherche, publiés ou non, émanant des établissements d'enseignement et de recherche français ou étrangers, des laboratoires publics ou privés. 


\title{
Toward a customized multicriterion tool for product evaluation in the early design phases: the CMDET methodology
}

\author{
Kévin Audoux ${ }^{1}{ }^{10} \cdot$ Frédéric Segonds $^{1} \cdot$ Olivier Kerbrat $^{2} \cdot$ Améziane Aoussat $^{1}$
}

\begin{abstract}
Owing to an increase in requirements and a reduction in time to market, evaluation phases have become particularly cru-cial steps in the design process, specifically during the early design stages. New domains of expertise are constantly being added to design processes, and the performance evaluation tools that are currently available are too heterogeneous to be used together. The differences mainly concern performance domains, which rely on different types of data. It is therefore necessary to create a methodology for merging compatible tools (i.e. usable during the same phase of the design process) and establishing the most appropriate form of evaluation. In this paper, we begin by describing the Creation of MultiDisciplinary Evaluation Tool methodology. This takes place in four stages: the analysis of existing tools, followed by their evaluation, selection and merger. This methodology will help designers create multicriterion evaluation tools that are tailored to their needs. We then report a case study involving the design of a sustainable and innovative product for additive manufacturing, where the characteristics of each domain were taken into account.
\end{abstract}

Keywords Early design stage $\cdot$ Evaluation methodology $\cdot$ Innovation $\cdot$ Sustainability $\cdot$ Additive manufacturing

\section{Introduction}

Early design phases are where innovation takes place, and where design choices have the most impact [1]. It is commonly accepted that $80 \%$ of the overall costs (environmental and/or economic) of a product are defined during these early design phases.

Designers therefore have to use assessment tools to evaluate their products' performances, in terms of cost, quality, functionality, manufacturability, environmental performance, and so on. As assessment tools are becoming more numerous, it is becoming difficult for designers to choose between them. At the same time, the number of considerations to take into account is also increasing, making the assessment phases increasingly difficult. We therefore propose a methodology for defining specific evaluation tools dedicated to individual

Kévin Audoux

kevin.audoux@ensam.eu

1 Laboratoire de Conception de Produits et Innovation, Arts et Métiers ParisTech, 151 Boulevard de l'Hôpital, 75013 Paris, France

2 Gem - UMR 6183, Univ Rennes CNRS, 35000 Rennes, France designers' needs. The Creation of MultiDisciplinary Evaluation Tool (CMDET) analyses the tools described in the literature, evaluates them in relation to a particular designer's specific needs, and finally merges the best ones to create a specific evaluation tool. The CMDET methodology has already been used to create a specific evaluation tool adapted to the early design phases, where the focus was on innovation, sustainable development, and additive manufacturing (AM).

Companies are increasingly taking sustainable development issues into account in the product development and production phases. Many methods have been developed to assess the lifecycles of design propositions, in order to select the product with the lowest environmental impact [2], but owing to the need for product data, this evaluation can only be made at the end of the design process, when each modification comes at a major cost [1]. Other studies focused on bringing about improvements in the production phase have sought to assess manufacturing processes [3, 4], and develop methods for managing these processes in order to reduce the overall impact of production [5]. The next target in the drive to reduce environmental impact in the course of product development needs to be the design process. For example, life-cycle analysis (LCA), the standardized and most widespread assessment method for environmental concerns, 
consumes a great deal of design resources. A product's environmental performance should therefore be assessed earlier, during the early design phases, and more quickly, in order to ensure greater efficiency. Designers must thus use a range of environmental impact assessment tools.

To design the best product, it is not enough just to analyse the environmental impact, as the product must meet innovation criteria if it is to match customers' needs and the firm's strategy. Designers therefore need to use innovation assessment tools.

In the case of nonconventional manufacturing processes, considering these processes during the early stages of design increases the designer's creativity [6]. The design rules for additive manufacturing (AM) are totally different from those for classic manufacturing. Early evaluation of the manufacturing potential allows designers to take this new technological paradigm into account. Designers must therefore use manufacturability assessment tools dedicated to AM. The research question is: how to evaluate intermediate representation regarding multi-disciplinary in the same stage of the design process?

The three levels of product performance assessment need to be brought together, so that designers can create products that are innovative, easy to produce by AM, and sustainable.

The interactive design appeared to join different engineering cultures [7]. The number of different disciplines involved in the design process makes it necessary to adapt an interactive approach i.e. an approach that facilitates the integration of new disciplines using expert tools.

Here, we present the CMDET methodology for creating a multicriterion evaluation tool. After describing the state of the art (Sect. 2), looking at how different aspects of performance are defined and how evaluations are carried out during design process, we present the CMDET methodology (Sect. 3), analysing (Sect. 3.1) and evaluating (Sect. 3.2) existing assessment tools, then selecting the best of these tools (Sect. 3.3) and creating a specific tool, dedicated to the designer's needs (Sect. 3.4). We then describe how this method was applied to create an evaluation tool for the early design phases, focusing on sustainability, innovation and AM (Sect. 4). In the Conclusion, we discuss future perspectives (Sect. 5).

\section{State of the art}

According to the literature [8-10], the design process involves innovation, especially in the early design phases [11]. The design process is defined as all the steps or actions between the problem and the product. According to Howard et al. [12], it can be modelled as four to six stages. In this paper, the design process is broken down into four stages: problem analysis, ideas research, development and industrialisation, as illustrated in Fig. 1.

This description of the state of the art focuses on the definition of performance, which lies at the heart of evaluation, particularly in the case of innovation, sustainability and AM.

\subsection{Definition of performance}

The definition of performance depends on two factors: the domain being studied and the design process phase being considered. A generic definition that is universally accepted is the quantitative measure of effectiveness and efficiency [13]. However, each area has its own definition of performance. For innovation, Shah [8] defined performance as the measure of the quality, quantity, novelty and variety of the ideas put forward during the design stages. For sustainability, performance is a combination of economic, environmental and societal performances [14]. As for manufacturing, Chenhall [15] defined performance as the quality of the product in relation to production costs.

To design a product that meets all requirements, performance has to be evaluated throughout the design process. The main problem of evaluation is the lack of data. As indicated earlier, the product is not sufficiently well defined during the early design stages, meaning that evaluations need specific methods and tools to be accurate. In the next three subsections, we focus on evaluation tools in three different domains: innovation, sustainability, and AM. The case study described in Sect. 4 looked at assessment across the four different design stages, in order to identify the different types of performance involved.

\subsection{Innovation performance}

The innovative aspect of a product is created during the early design phases [8]. We can differentiate between two kinds
Fig. 1 Design process and position of innovation. Adapted from $[8,12]$

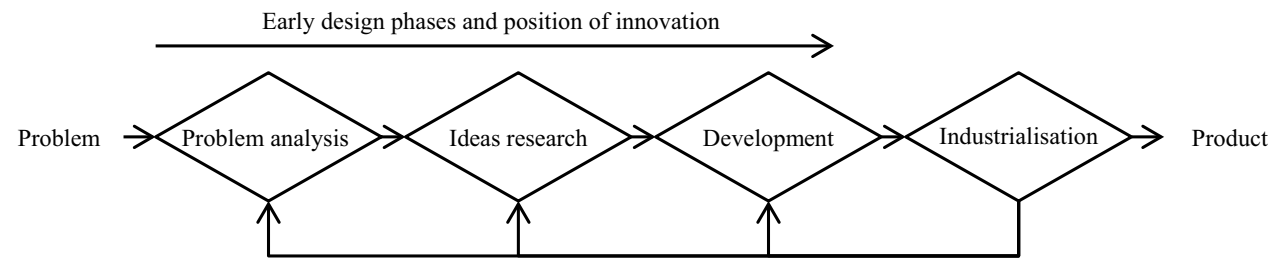


of innovation: incremental innovation, which improves an existing product [16], and breakthrough innovation, which results in new products to meet new needs $[9,17]$.

Innovation can be assessed during the design process in two different ways:

- Assessment of organisational potential, evaluating the firm's capacity to carry out the design project. The assessment tools are economic, and look at the potential success of the project without studying the data on the design process;

- Assessment of the design process potential, which can be defined as the evaluation of different intermediate representations of the product during the early design phases. This is the one targeted in this paper, as it is based on tangible data.

Given its position in the design process (Fig. 1), innovation needs to be evaluated during the first three stages: problem analysis, ideas research and development. The main problem is the lack of data during these early stages.

In the problem analysis stage, the design is reduced to the definition of the specifications, making it difficult for designers to identify the opportunities and drive the design process in the right direction. However, this stage allows the indicators of performance to be defined for the following stages, as Binz and Reichle noted for the assessment of the product concept [18].

In the ideas research stage, creative tools are used to conduct the search process. It is crucial to evaluate ideas, in order to select the best one. This can be performed via two types of evaluation:

- Expert evaluation designers rely on experts to set the design objectives. According to Zimmer et al. [19], the early selection of design ideas by experts is crucial for reducing design time and obtaining the best product at the end of the design process. Experts identify the potential of the design project according to four characteristics (utility, innovation, profitability and concept);

- Tool evaluation designers can evaluate the intermediate representations of their product by themselves, using specific tools. It is essential to use objective criteria. For Saunders et al. [16], innovative products have similarities, so an in-depth study of successful products allows characteristics to be extracted to evaluate fresh ideas.

The development stage is the last one where innovation evaluation is available and useful. The data are more meaningful and, most of all, the evaluation can be based on a classic method such as the function matrix, to compare the concepts with function goals or target characteristics. According to Binz and Reichle [18], the assessment of functions by future users allows the future product's acceptability to be tested, and therefore helps to improve its innovative aspect.

In this section, we indicate the position of the different innovation evaluation methods and tools in the design process. Each method has different needs and goals, depending on its position in the process. This state-of-the-art review is not exhaustive, but makes it possible to explore how and when innovation is evaluated in the design process.

\subsection{Sustainable performance}

Sustainability means considering three aspects: social, environmental and economic. Performances in these three areas can be evaluated throughout the whole design process, using the Design For X (DfX) method of assessing sustainability (Design for Sustainability, DfS) [20, 21], where X is a lifecycle phase (e.g. Design for Environment) or an aspect of sustainability (e.g. Design for Recyclability). Evaluation methods depend on the quantity and quality of the data, and are therefore linked to the stage of the design process. As with innovation performance (see previous section), sustainable performance evaluation can be broken down according to the different design process stages.

In the problem analysis stage, sustainability is linked to the design goals. Here, the methods are used either to provide basic knowledge, as summed up in the 10 Golden Rules [22], or to establish the goals for redesigning products in an attempt to make them more environmentally friendly, as Cluzel et al. mentioned [23].

In the ideas research stage, the evaluation methods are similar to those to assess innovation, and based on the product's creative aspect. Some methods adapt creativity tools so that they include an environmental aspect [24], or to ask designers about sustainability indicators [25].

In the development stage, evaluation methods are used to assess the product's architecture. This evaluation can be used to compare concepts on sustainability indicators [26] or compare components in order to select the best one in terms of sustainable performance [27].

In the industrialisation stage, LCA is the common and standardized method. It is, however, complex, owing to the amounts of time and data needed. Some methods have been developed to simplify product evaluation during this phase, by recommending different indicators or breaking LCA down into different lifecycle phases (e.g. manufacturing), and suggesting that the processes should each be evaluated, in order to compare them [28].

The sustainability evaluation method allows the design process to be monitored. The problem is that the evaluation is not continuous, and requires just as many methods as design stages. This state-of-the-art review is not exhaustive, but makes it possible to see how the issue of sustainability evaluation fits into the design process. 


\subsection{Additive manufacturing performance}

The evaluation of manufacturing performance is defined as the evaluation of the product or its representation according to its capacity to be manufactured using the proposed process [15]. It consists in determining whether the product is properly designed for a specific manufacturing process and whether the design rules are respected. It is carried out during the later design stages, in order to validate the process and the CAD product.

Implemented during the ideas research stage, the Design With Additive Manufacturing (DWAM) tool developed by Laverne [29] is intended to integrate AM knowledge during the early stages, in order to increase the product's creativity and the innovation level of intermediate representations, and then to evaluate its potential. As Rias' proposal underlines, during the search for ideas stage, there are insufficient product data to analyse the product's manufacturability, so experts may have to be called into analyse its potential [30]. Ideas can be evaluated with adapted tools, like those developed by Booth [31], taking the form of a matrix where design rules are graphically formulated to evaluate the AM potential.

In the development stage, the amount of data defining the product increases, and many AM evaluation methods can be found in the literature. The product's architecture can be evaluated with a view to being manufactured using AM processes. The Design By Additive Manufacturing (DBAM) methodology [32] uses the potential of the AM paradigm as assessment criteria and suggests an optimization tool in order to fulfil the AM process requirements. Methodologies are available for evaluating CAD parts, to analyse whether the geometry suits the process characteristics (e.g. building layers, part orientation or shell thickness [33].

During the industrialisation stage, AM performance is included in an overall Design For Additive Manufacturing (DFAM) methodology [34]. DFAM methods are aimed at optimizing the product, so that it can easily be manufactured using the AM process. These kinds of methods are applied during the later design stages to validate the industrialization proposal. Laverne et al. [35] distinguish between two types of DFAM methods: part-oriented and assembly-oriented optimization. Both types analyse the CAD model in order to identify its geometry and set it against design rules and design goals. DFAM is generally used to reduce the mass or volume of the material used [36].

The literature does not contain any AM evaluation methods for problem analysis. Manufacturing processes are regarded as a way of meeting requirements, rather than as an opportunity.

Performance in manufacturing is mostly evaluated in the final stages of the design process. However, assessing performance in the early design stages would make it possible to select intermediate representations that take full advantage of the possibilities offered by AM. Designers must therefore radically change their evaluation methods if their products are to be adapted to this new process. This state-of-the-art review, while not exhaustive, raises the issue of exactly when manufacturing, especially AM, should be assessed in the course of the design process.

\subsection{Synthesis}

This state of the art shows that the number of assessment tools is steadily increasing, and it is becoming difficult for designers to choose between them. These tools do not all have the same purpose, as it depends on how they are used in the design process and the area of expertise. As shown in the previous sections, evaluation during the design process is contingent not only on the domain of expertise, but also on the point at which it is applied during the design process. The present state of the art indicates that, in order to properly assess the performance of a product, designers need to:

- Evaluate the product as early as possible in the design process. However, this is not possible with all the traditional tools, as they often require data that arrive later on;

- Rely on tools, as it is not always easy to use experts, especially when looking at different areas of performance.

Designers therefore need to be offered an interactive method that allows them to create their own evaluation tools, according to their domains of expertise. The method we set forth in the following sections is based on an analysis of the literature.

The following methodology is based on an interactive approach. Each step of the proposal is generalized to fit to each disciplinary and each design process stage.

\section{Creation of MultiDisciplinary Evaluation Tools (CMDET) methodology}

The Creation of MultiDisciplinary Evaluation Tools (CMDET) methodology will allow designers to create a multicriterion assessment tool that is tailored to their particular needs. These needs vary according to the domain of expertise and the stage in the design process. The objective of the CMDET methodology is to create an MultiDisciplinary Evaluation Tool (MDET) from a list of performance domains that need to be evaluated in a design project, as shown in Fig. 2. 


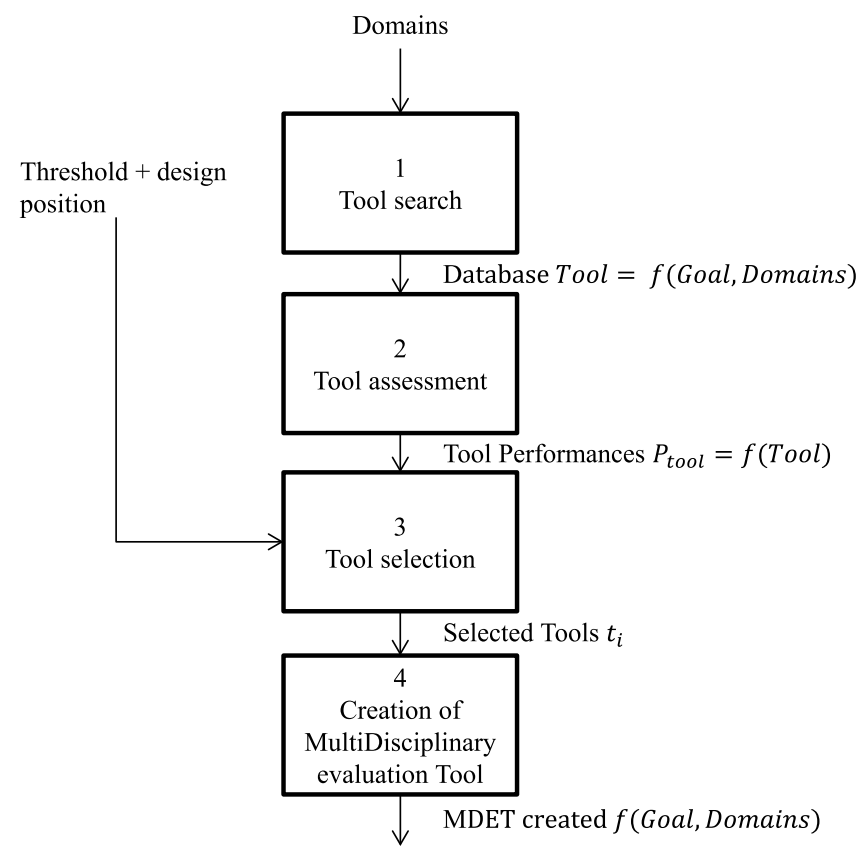

Fig. 2 Creation of MultiDisciplinary Evaluation Tools (CMDET) methodology

\subsection{Tool search}

To validate the objectives, the focus must first be on the analysis of existing tools, in order to select those most suited to extracting the information and outputs needed to create a multicriterion evaluation method. This is why the first stage of the methodology concerns the search for existing assessment tools in the literature, depending on which domains the designer wants to assess (e.g. innovation, sustainability, manufacturability, maintenance, recycling, lifecycle costing, etc.).

A database is then created, where the tools are classified according to the domains of the design project and the relevant stage in the design process.

\subsection{Tool assessment}

\subsubsection{Tool assessment criteria}

Once existing tools have been found in the literature, the task is to select the ones that best meet the designer's needs. This assessment method is based on four criteria:

- Design process position (DPP).

- Facility of using the tool (F).

- Benefit of the tool (B).

- External data constraint (EDC).

These criteria were chosen because they are nonspecific and can therefore be used for the different domains of the

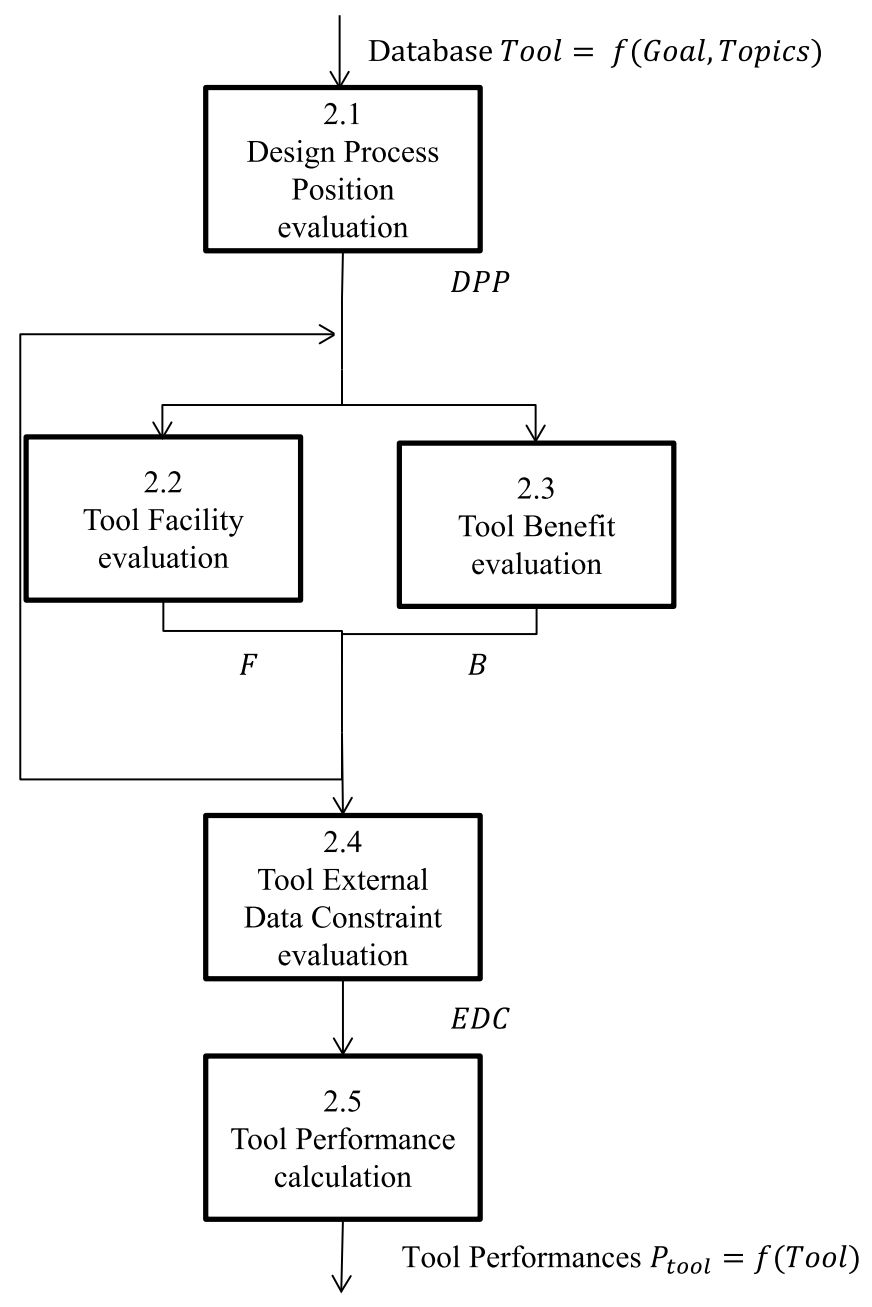

Fig. 3 Tool assessment method

design project. DPP helps to find out which design stage is concerned by the tool. $\mathrm{F}$ makes it possible to evaluate the need for expertise to use the tool. B is used to classify the different kinds of tool, as proposed by Bovea and Pérez-Belis [37]. EDC shows the amount of data needed to create the performance indicators.

The tools are assessed in five steps, using the method illustrated in Fig. 3.

\subsubsection{Design process position evaluation}

In this step, the tools are classified according to the stage in the design process (problem analysis, ideas research, development and industrialisation; see Fig. 1). DPP criteria are then assigned to the tool. If the tool is useful for more than one design stage, Steps 2.1-2.5 are completed for each stage.

\subsubsection{Tool facility and benefit evaluation}

In this step, the F and B criteria are applied to the tool for the relevant design stage, as set out in Table 1. 
Table 1 Evaluation grid for $\mathrm{F}$ and $\mathrm{B}$ criteria

\begin{tabular}{lll}
\hline Value & Evaluation of facility & Evaluation of benefit \\
\hline 0 & The tool is not used at this stage & The tool is not used at this stage \\
1 & Expertise and long skilling time are needed & Pros and cons are identified by the tool \\
2 & Expertise or long skilling time is needed & Indicators of performance are provided by the too \\
3 & Knowledge of the field is required and/or skilling time is needed & Guidelines for improvement are provided by the tool \\
4 & No expertise/knowledge is needed, or only a short skilling time & Potential improvements are proposed by the tool \\
5 & No expertise/knowledge is needed, and only a short skilling time & A better performance solution is provided by the tool \\
\hline
\end{tabular}

Table 2 EDC evaluation grid

\begin{tabular}{ll}
\hline Value & Evaluation of external data constraint \\
\hline 0.5 & Redesign: needs data on previous product \\
1 & Needs data on previous stage option \\
2 & Independent of external data \\
\hline
\end{tabular}

\subsubsection{Tool external data constraint evaluation}

In this step, the tool's EDC is evaluated, in accordance with Table 2. Calculating the EDC helps to identify tools that require a large amount of external data (e.g. complete definition of a previous product when the tool is based on comparisons with different products to assess performance).

\subsubsection{Tool performance calculation}

The tool performance $\left(P_{\text {tool }}\right)$ calculation is done according to Eq. (1)

$P_{\text {tool }}=(F+B) \times E D C$

This equation is used to distinguish between the tools, by setting their intrinsic qualities of facility and benefit against their need for external data, which is a defect. The best adapted tool is the one with the highest $P_{\text {tool }}$ value.

\subsection{Tool selection}

Once all the tools have been evaluated, the best ones can be selected. The goal of this step is to establish the threshold for selection and identify the DPP of the future MDET. An example is given in the case study section (Sect. 4.3).

\subsection{MultiDisciplinary Evaluation Tool (MDET) creation}

The MDET is created in two separate steps, as shown in Fig. 4.

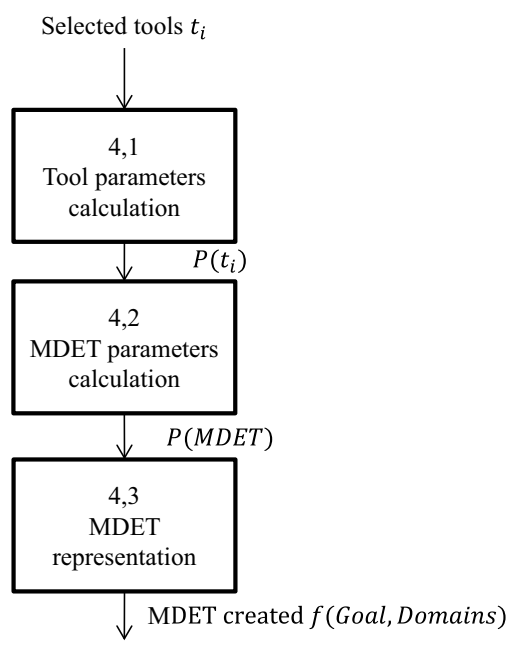

Fig. 4 Creation of the MDET

\subsubsection{Tool parameters calculation}

After the $N$ best tools have been selected (noted $t_{i}$ with $i \in[1 \ldots N])$ in Step 3, Step 4 of the CMDET methodology is the creation of the MDET. In order to limit subjectivity in determining the overall tool, a more accurate characterization of the tools to be merged is needed.

Each selected tool is therefore divided into six parameters that serve to describe the data used and their operation. These parameters describe the tool when considering input data (internal and external $P_{1}$ and $\left.P_{4}\right)$, output data $\left(P_{6}\right)$ and three internal steps (identification of criteria $P_{2}$, establishment of design rules $P_{3}$, and proposed evaluation $P_{5}$ ). Each parameter is associated with its own calculation model.

In Fig. 5, each tool $t_{i}$ is defined by six parameters $P_{1}\left(t_{i}\right)$ to $P_{6}\left(t_{i}\right)$. Accordingly, the MDET is also characterized by these six parameters $P_{1}(M D E T)$ to $P_{6}(M D E T)$.

The parameter $P_{1}\left(t_{i}\right)$ defines the nature of the data available during the relevant stage of the design process. This parameter therefore depends directly on the DPP, and the different values are:

- If the design stage concerned by the tool $t_{i}$ is problem analysis, then $P_{1}\left(t_{i}\right)=1$. 


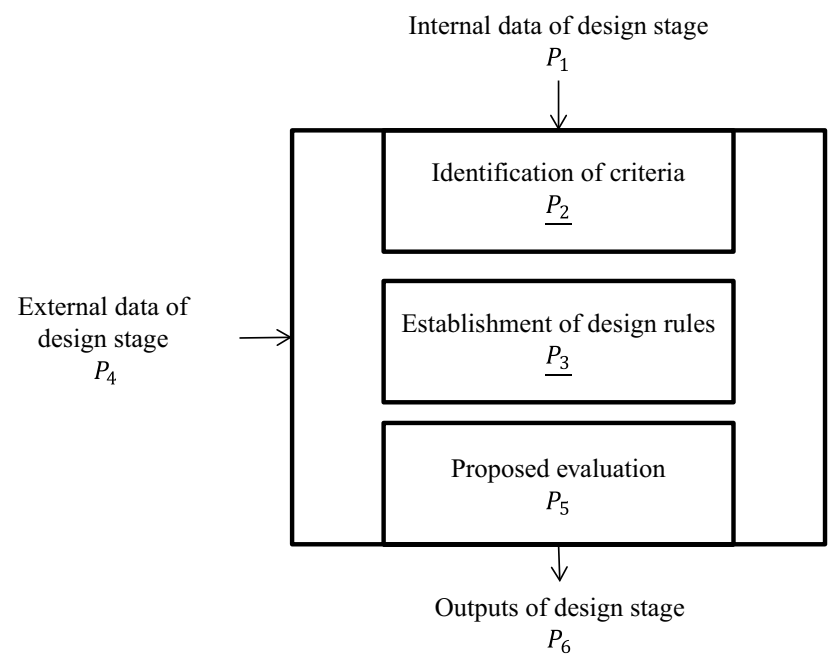

Fig. 5 Parametrization of the tools

- If the design stage concerned by the tool $t_{i}$ is ideas research, then $P_{1}\left(t_{i}\right)=2$.

- If the design stage concerned by the tool $t_{i}$ is development, then $P_{1}\left(t_{i}\right)=3$.

- If the design stage concerned by the tool $t_{i}$ is industrialisation, then $P_{1}\left(t_{i}\right)=4$.

The parameter $P_{2}\left(t_{i}\right)$ is used to describe how the tool analyses and selects the criteria for the evaluation. It is composed of a vector with $D$ coordinates, where $D$ is the number of domains concerned by the evaluation. In the case study discussed in this paper, $D$ was 3 , as the design project specifically focused on three domains: Innovation/Sustainability/AM. For example:

- If the tool $t_{i}$ only evaluates innovation and uses a single criterion for this, then $\underline{P_{2}\left(t_{i}\right)}=\left(\begin{array}{l}1 \\ 0 \\ 0\end{array}\right)$ and note $p_{2,1}\left(t_{i}\right)=1, p_{2,2}\left(t_{i}\right)=0, p_{2,3}\left(t_{i}\right)=0$.

- If the tool $t_{i}$ only evaluates sustainability and uses two criteria for that, then $\underline{P_{2}\left(t_{i}\right)}=\left(\begin{array}{l}0 \\ 2 \\ 0\end{array}\right)$ and note $p_{2,1}\left(t_{i}\right)=0, p_{2,2}\left(t_{i}\right)=2, p_{2,3}\left(t_{i}\right)=0$.

- If the tool $t_{i}$ evaluates both innovation and AM, and uses one criterion for each domain, then $\underline{P_{2}\left(t_{i}\right)}=\left(\begin{array}{l}1 \\ 0 \\ 1\end{array}\right)$ and note $p_{2,1}\left(t_{i}\right)=1, p_{2,2}\left(t_{i}\right)=0, p_{2,3}\left(t_{i}\right)=1$.

The parameter $P_{3}\left(t_{i}\right)$ is used to describe how the tool translates the selected criteria into design rules for the design phase. For example, if the tool $t_{i}$ only evaluates sustainability using the design rule "Use only reusable materials", then $\underline{P_{3}\left(t_{i}\right)}=\left(\begin{array}{l}0 \\ 1 \\ 0\end{array}\right)$ and note $p_{3,1}\left(t_{i}\right)=0, p_{3,2}\left(t_{i}\right)=1, p_{3,3}\left(t_{i}\right)=0$.

The parameter $P_{4}\left(t_{i}\right)$ quantifies the external data needed for the evaluation and is based on the EDC criterion. For example, if tool $t_{i}$ requires four items of external data for the evaluation, then $P_{4}\left(t_{i}\right)=4$.

The parameter $P_{5}\left(t_{i}\right)$ describes how the design rules are turned into an evaluation tool, be it a questionnaire, a matrix, or a comparison. For example:

- If the tool is a questionnaire, then $P_{5}\left(t_{i}\right)=1$.

- If the tool is a matrix, then $P_{5}\left(t_{i}\right)=2$.

- If the tool is a comparison tool, then $P_{5}\left(t_{i}\right)=3$.

The parameter $P_{6}\left(t_{i}\right)$ defines the nature of the data at the end of the design stage being studied. The different values are:

- If the design stage concerned by the tool $t_{i}$ is problem analysis, then $P_{6}\left(t_{i}\right)=1$.

- If the design stage concerned by the tool $t_{i}$ is ideas research, then $P_{6}\left(t_{i}\right)=2$.

- If the design stage concerned by the tool $t_{i}$ is development, then $P_{6}\left(t_{i}\right)=3$.

- If the design stage concerned by the tool $t_{i}$ is industrialisation, then $P_{6}\left(t_{i}\right)=4$.

\subsubsection{MDET parameters calculation}

Once these six parameters have been defined for each of the selected tools, the relevant parts of each tool are selected to create the MDET. This tool is therefore characterized by six parameters calculated according to Eqs. 2-7 below.

As the MDET is created for a single design stage, the selected tools all have the same DPP. So all $P_{1}\left(t_{i}\right)$ and all $P_{6}\left(t_{i}\right)$ are equal for the selected tools. In future research, the MDET could be based on tools from different design stages.

$P_{1}(M D E T)=P_{1}\left(t_{i}\right)$

$\underline{\mathrm{P}_{2}(M D E T)}=\left(\begin{array}{c}\sum_{k_{1}=1}^{n_{F_{1}}} p_{2,1}\left(t_{k_{1}}\right) \\ \ldots \\ \sum_{k_{D}=1}^{n_{F_{D}}} p_{2, D}\left(t_{k_{D}}\right)\end{array}\right)$

where $t_{k_{j}}$ are the tools that best meet criterion $F$ for domain $j$, and $n_{F_{i}}$ is the number of tools involved. For this calculation, therefore, only those tools $t_{i}$ that have been judged in terms of ease of use are used. 
$\underline{\mathrm{P}_{3}(M D E T)}=\left(\begin{array}{c}\sum_{k_{1}=1}^{n_{F_{1}}} p_{3,1}\left(t_{k_{1}}\right) \\ \ldots \\ \sum_{k_{D}=1}^{n_{F_{D}}} p_{3, D}\left(t_{i}\right)\end{array}\right)$

where $t_{k_{j}}$ are the tools for which the parameter $F$ is best for the domain $j$, and $n_{F_{i}}$ is the number of tools involved.

$P_{4}(M D E T)=\sum_{j=1}^{D} \sum_{k=1}^{N} P_{4}\left(t_{k_{j}}\right)$

where $t_{k_{j}}$ are the tools for which parameter $F$ is best for domain $j$, and $n_{F_{i}}$ is the number of tools involved.

$P_{5}(M D E T)=P_{5}\left(t_{i}\right) i f F\left(t_{i}\right)=\operatorname{Max}\left\{F_{t_{i}}\right\}$

$P_{6}(M D E T)=P_{6}\left(t_{i}\right)$

\subsubsection{MDET representation}

The MDET is represented in the same way as the tools (Fig. 5). It is now ready to be used by the designer to assess the product being designed-a unique evaluation tool dedicated to the designer's needs.

\section{Case study}

The robustness and viability of the CMDET methodology has been tested on several occasions, where different types of performance had to be assessed for a particular product design project. In the following sections, we describe one particular case study where the MDET was used to evaluate the innovation, sustainability and AM potential of an innovative phone case in an early design stage.

These three areas were chosen because:

- Innovation makes a product stand out from competing ones.

- Sustainability reduces the product's environmental impact.

- AM takes advantage of the emergence of 3D printers and allows a service to be offered, not just a product.

\subsection{Tool search}

The different tools we assessed in this case study were taken from the scientific literature and were designed to assess innovation, sustainability, and AM during the design process.
These tools, classified by domain (main domain/secondary domain), are described in Table 3 . We refer to them using Greek letters when they deal mainly with innovation, capital letters when they evaluate sustainability, and roman numerals when they concern AM.

\subsection{Tool assessment}

The assessment involved 29 different evaluation tools (8 for innovation, 16 for sustainability, and 9 for AM). Some tools dealt with two domains, but for clarity's sake, we only retained the main domain.

Each tool was evaluated, and the best ones were selected according to the methodology set out in Fig. 3. Tool performance was evaluated according to Eq. 1. In Fig. 6, the performance of each tool is modelled as the length of a coloured bar and situated in one of the four design stages. The colour is blue when the tool dealt mainly with innovation (green for sustainability and yellow for AM).

The minimum value obtained was 2 (Tool II) and the maximum value obtained was 14 (Tools $\alpha, \mathrm{F}, \mathrm{IV}, \mathrm{J}, \mathrm{V}, \mathrm{H}$ and $\mathrm{D}$ ), although the theoretical maximum value was 20 . This gap can be explained by the inability of the existing tools to find an optimum solution without requiring time or expertise.

Results were in line with the state of the art: innovation was evaluated in the early design stages; sustainability was monitored throughout the process; and AM was studied in the later phases.

\subsection{Tool selection}

In order to evaluate the product, the tools were selected by taking into account the top third of all the evaluation tools and the evaluation tools dealing with ideas research. Four tools $t_{1-4}$ were retained:

- $t_{1}=\beta$, characteristics of innovative products [16].

- $t_{2}=\mathrm{F}$, total lifecycle considerations [20].

- $t_{3}=$ IV, DFAM worksheet [31].

- $t_{4}=\alpha$, eco-ideation [23]

\subsection{MDET creation for the assessment of innovation, sustainability and AM performance during early design stages}

\subsubsection{Tool parameter calculation}

Tool $t_{1}$ was used for ideas research stage, so $P_{1}\left(t_{1}\right)=P_{6}\left(t_{1}\right)=2$. The evaluation of innovation was based on five types of criteria $\left(P_{2}\left(t_{1}\right)=[5,0,0]\right)$ divided into 12 design rules $\left(P_{3}\left(t_{1}\right)=[1 \overline{2,0,0]})\right.$. To create the criteria, the 
Table 3 Evaluated tools

\begin{tabular}{|c|c|c|c|c|}
\hline \multirow[t]{2}{*}{ Name } & \multirow[t]{2}{*}{ References } & \multicolumn{2}{|c|}{ Domain } & \multirow[t]{2}{*}{ ID } \\
\hline & & $1 \mathrm{st}$ & 2nd & \\
\hline 10 golden rules in EcoDesign & {$[22]$} & $\mathrm{S}$ & & A \\
\hline Eco-innovation & {$[24]$} & I & $\mathrm{S}$ & $\eta$ \\
\hline Eco-ideation & {$[25]$} & I & $\mathrm{S}$ & $\alpha$ \\
\hline Sustainable product design model & {$[38]$} & $\mathrm{S}$ & & $\mathrm{B}$ \\
\hline Eco innovative & [39] & $\mathrm{S}$ & & $\mathrm{C}$ \\
\hline Sustainable manufacturing & {$[40]$} & $\mathrm{S}$ & $\mathrm{AM}$ & $\mathrm{D}$ \\
\hline Total life-cycle considerations & {$[20]$} & $\mathrm{S}$ & & $\mathrm{F}$ \\
\hline Roadmap for predicting product end-of-life costs & {$[41]$} & $\mathrm{S}$ & & G \\
\hline MA-AHP approach for selecting the highest sustainability index & {$[26]$} & $\mathrm{S}$ & & $\mathrm{H}$ \\
\hline Economics of AM for end-usable metal parts & {$[42]$} & $\mathrm{S}$ & $\mathrm{AM}$ & I \\
\hline Streamlined LCA framework & {$[28]$} & $\mathrm{S}$ & & $\mathrm{J}$ \\
\hline Quality function deployment for optimum environmental performance improvement & [27] & $\mathrm{S}$ & & $\mathrm{K}$ \\
\hline Environmental performance strategy map & [43] & $\mathrm{S}$ & & $\mathrm{L}$ \\
\hline Environmental performance evaluation and indicators & [44] & $\mathrm{S}$ & & M \\
\hline LCA & [2] & $\mathrm{S}$ & & $\mathrm{N}$ \\
\hline $\mathrm{CO} 2 \mathrm{PE} !$ & [3] & $\mathrm{S}$ & $\mathrm{AM}$ & $\mathrm{P}$ \\
\hline Characteristics of innovative, mechanical products & {$[16]$} & I & & $\beta$ \\
\hline Radical innovation project selection model & [9] & I & & $\gamma$ \\
\hline Innovation evaluation & {$[18]$} & I & & $\delta$ \\
\hline Supporting product design by anticipating the success chances of new value profiles & {$[45]$} & I & & $\varepsilon$ \\
\hline A method to set up a complexity index to improve decision making performance & {$[46]$} & I & & $\zeta$ \\
\hline Topology optimization & [36] & $\mathrm{AM}$ & & VIII \\
\hline Adding product value & {$[47]$} & $\mathrm{AM}$ & & II \\
\hline DFAM & [34] & $\mathrm{AM}$ & & III \\
\hline DWAM & [29] & $\mathrm{AM}$ & & VII \\
\hline Design for laser AM & {$[33]$} & $\mathrm{AM}$ & & $\mathrm{V}$ \\
\hline Creative early DFAM & {$[30]$} & $\mathrm{AM}$ & I & VI \\
\hline DFAM worksheet & {$[31]$} & $\mathrm{AM}$ & & IV \\
\hline Eco-innovation dashboard & {$[10]$} & I & $\mathrm{S}$ & $\theta$ \\
\hline
\end{tabular}

This table sets out the results of our review of the state of the art, which did not seek to be exhaustive, but instead to summarize the most common tools in the literature

tool relied on the study of successful innovative products $\left.\left(P_{4}\left(t_{1}\right)=1\right)\right)$. The evaluation yielded a binary result for each rule $\left(P_{5}\left(t_{1}\right)=1\right)$. Tool $t_{1}$ is represented in Fig. 7 .

Tool $t_{2}$ was used to quantify the impact of intermediate representations on the search for ideas research $\left(P_{1}\left(t_{2}\right)=P_{6}\left(t_{2}\right)=2\right)$. The evaluation of sustainability was based on three types of criteria $\left(P_{2}\left(t_{2}\right)=[0,3,0]\right)$ divided into 12 design rules $\left(P_{3}\left(t_{2}\right)=[\overline{0,12,0}]\right)$. To establish the criteria, the tool needed to explore the product requirements and product environment $\left(P_{4}\left(t_{2}\right)=2\right)$. The result of the evaluation was a matrix $\left(P_{5}\left(t_{2}\right)=2\right)$. Tool $t_{1}$ is represented in Fig. 8.

Tool $t_{3}$ was used for ideas research stage $\left(P_{1}\left(t_{3}\right)=P_{6}\left(t_{3}\right)=2\right)$. The evaluation of AM was based on four types of criteria $\left(P_{2}\left(t_{3}\right)=[0,0,4]\right)$ divided into eight design rules $\left(P_{3}\left(t_{3}\right)=\overline{[0,0,8]}\right)$. To establish the criteria, the tool needed to study the possibilities of the AM process $\left(P_{5}\left(t_{3}\right)=1\right)$. The result of the evaluation was a graphic representation of a Likert scale evaluation. Tool $t_{3}$ is represented in Fig. 9.

Tool $t_{4}$ was used for ideas research stage $\left(P_{1}\left(t_{4}\right)=P_{6}\left(t_{4}\right)=2\right)$. The evaluations of innovation and sustainability were each based on five types of criteria $\left(P_{2}\left(t_{4}\right)=[5,5,0]\right)$, divided into ten design rules $\left(\underline{P_{3}\left(t_{4}\right)}=[10,10,0]\right)$. To establish the criteria, the tool needed to study the product requirements $\left(P_{5}\left(t_{4}\right)=1\right)$. The result of the evaluation was a three-level survey for each rule. Tool $t_{4}$ is represented in Fig. 10.

Table 4 sums up the tools' parameters. 


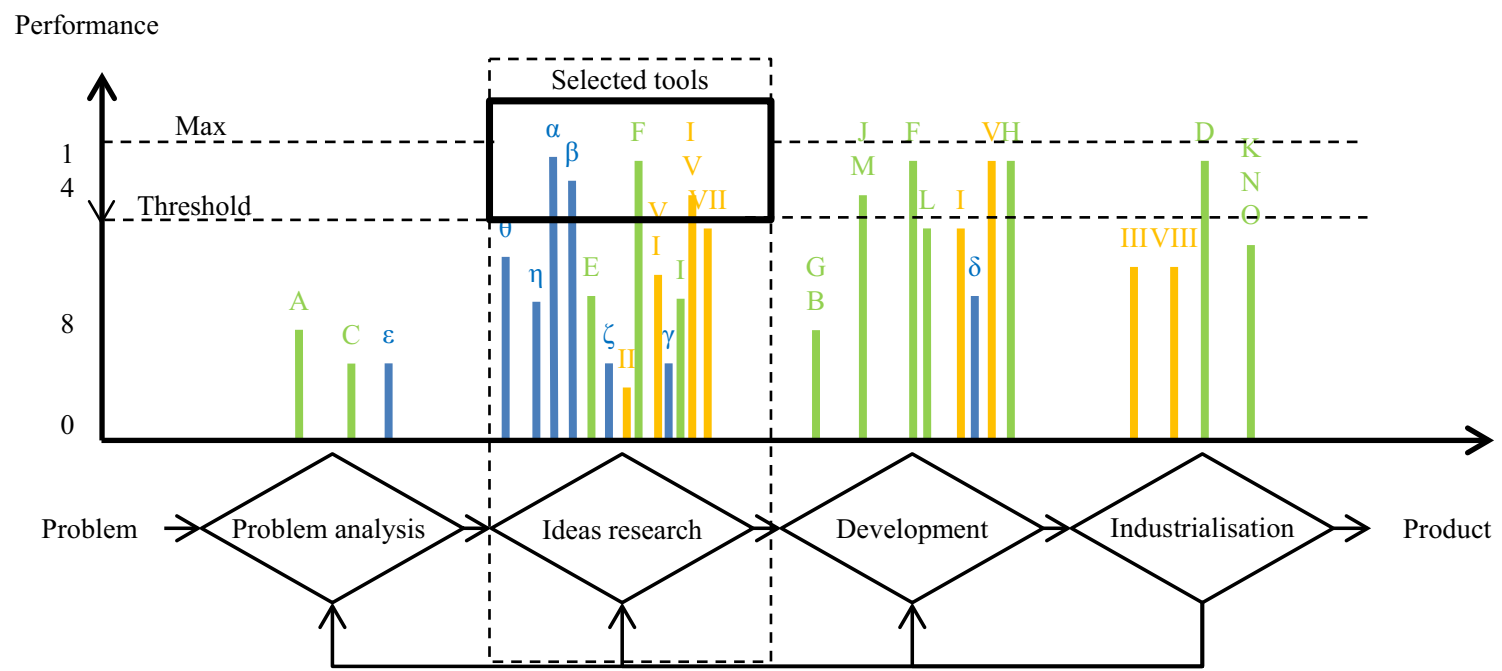

Fig. 6 Results of tool evaluation in the case study on how to evaluate the innovation, sustainability and additive manufacturing potential of an innovative phone case in the early design stages

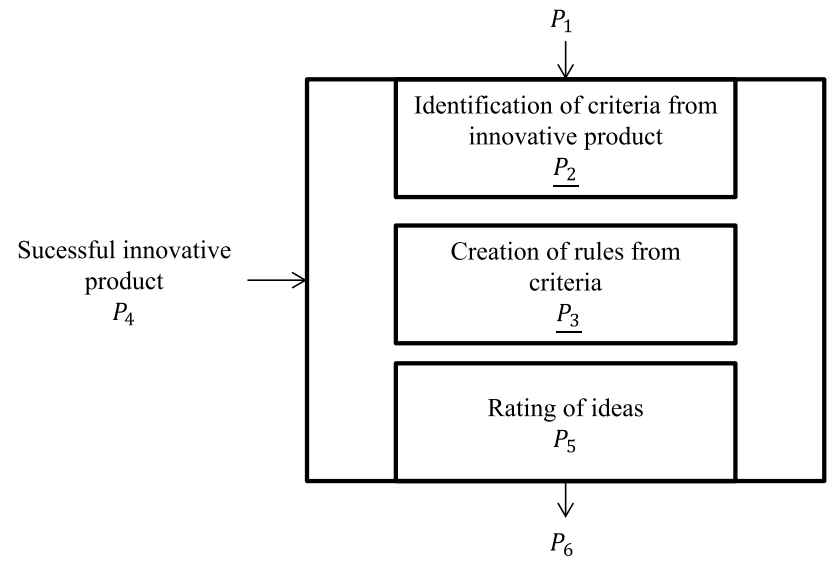

Fig. 7 Parametrization of $t_{1}$

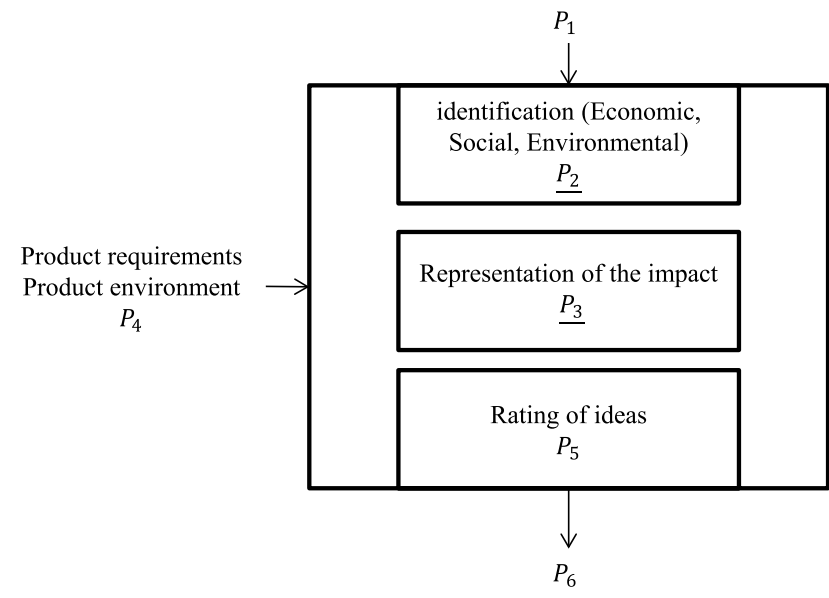

Fig. 8 Parametrization of $t_{2}$

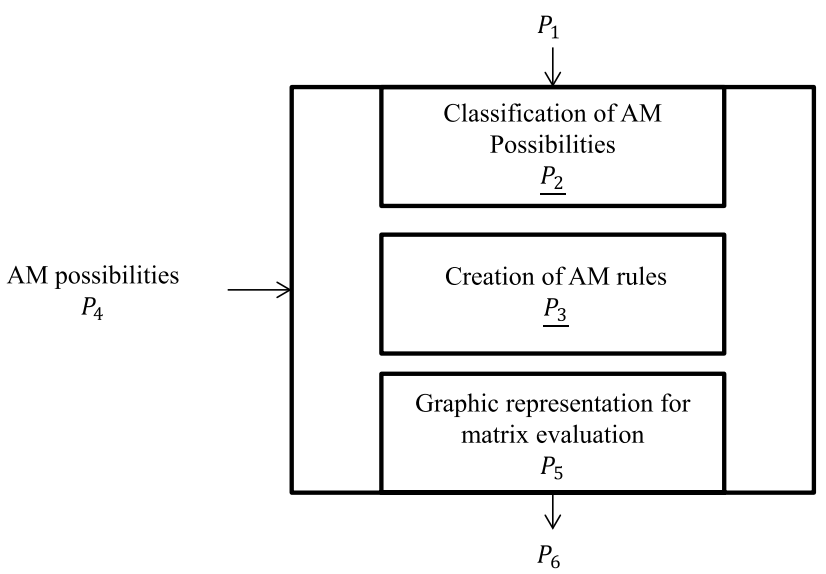

Fig. 9 Parametrization of $t_{3}$

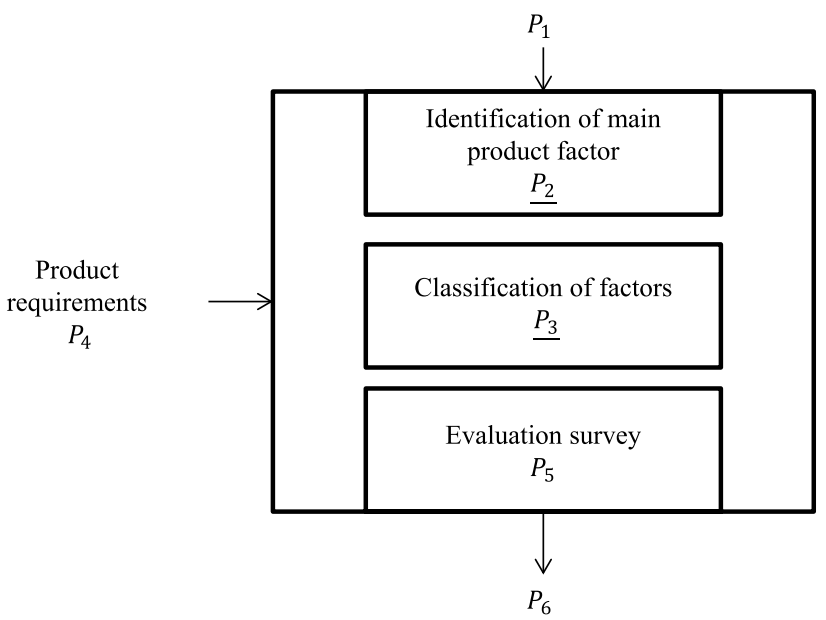

Fig. 10 Parametrization of $t_{4}$ 
Table 4 Parametrization of tools and MDET

\begin{tabular}{llllll}
\hline Tool & $t_{1}$ & $t_{2}$ & $t_{3}$ & $t_{4}$ & MDET \\
\hline$P_{1}$ & 2 & 2 & 2 & 2 & 2 \\
$P_{2}$ & $(5,0,0)$ & $(0,3,0)$ & $(0,0,4)$ & $(5,5,0)$ & $(5,3,4)$ \\
$\frac{P_{3}}{P_{4}}$ & $(12,0,0)$ & $(0,12,0)$ & $(0,0,8)$ & $(10,10,0)$ & $(12,7,8)$ \\
$P_{5}$ & 3 & 2 & 1 & 2 & 1 \\
$P_{6}$ & 2 & 3 & 3 & 1 & 1 \\
\hline
\end{tabular}

\subsubsection{Calculation of MDET}

We used three of the four selected tools $t_{1}, t_{2}$ and $t_{3}\left(n_{F}=3\right)$ to establish the criteria and transcribe them as design rules (one for each evaluated domain). Tool $t_{4}$ was used to transpose the design rules into an evaluation.

The parameters for the MDET were calculated according to Eqs. 2-7, and the results are set out in Table 4.

\subsubsection{MDET representation}

The MDET parametrization and model are represented in Fig. 11.

The MDET was then implemented as a numerical tool for use by the designer carrying out the design project concerned by the case study. It contained all the classic options (project management, customisation of tools). It is illustrated in Fig. 12, where the DPP indicates the type of intermediate representation the designer evaluated. Each criterion of $t_{1}, t_{2}$ and $t_{3}$ was divided according to the associated design rules. In order to satisfy the $t_{4}$ tool, each level of evaluation was completed by a definition. The evaluation is monitored during all the stage.

\section{Conclusion and perspectives}

This paper sets out the limitations and possibilities of performance evaluation during the design process. Our review of the state of the art showed that performance has many definitions, depending on which domain is being studied. Given the multiple representations of the product during the design process, it is difficult to evaluate it during the early design stages. We therefore developed the CMDET methodology, which involves analysing the literature in order to identify the best evaluation tools for each design process stage and for multiple domains. The selection method can be used on its own. The goal of the CMDET methodology is to create a multicriterion evaluation tool. It is implemented in a numerical tool and used during design projects. CMDET methodology provide for the case study of a phone case an evaluation tool adapted to a specific design stage and regarding three different domains (innovation, sustainability and additive manufacturing).

This methodology is a part of a more global one for carrying out multicriterion improvements in the early design stages. The objective of future research will be to validate the evaluation tool elaborated with this methodology and provide to designers DfX adapted to the needs of the intermediate representation as shown on the Fig. 12. We are planning to conduct a full design project to validate the different steps of the overall methodology. Ultimately, this methodology will provide assessment tools tailored to each

Fig. 11 MDET representation

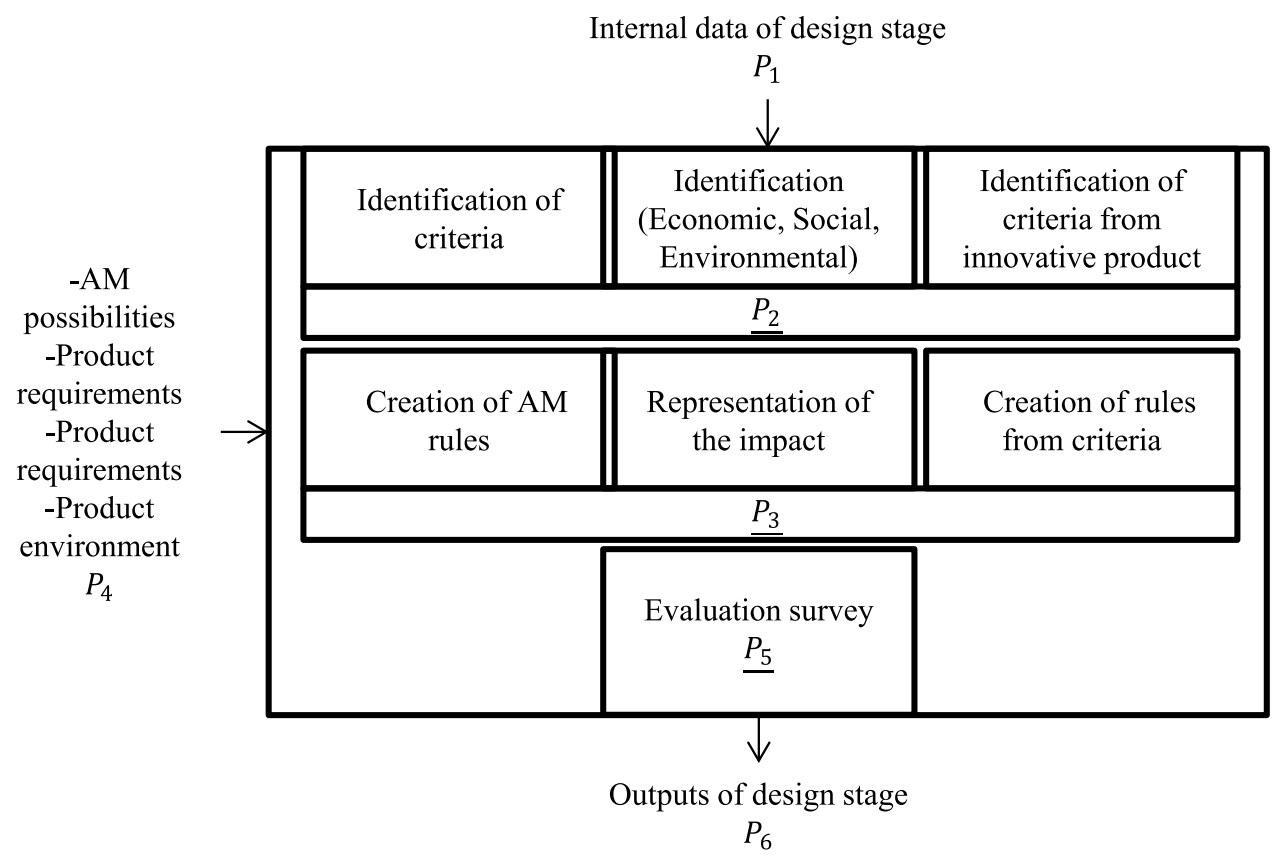


Fig. 12 Screenshot of the numerical MDET

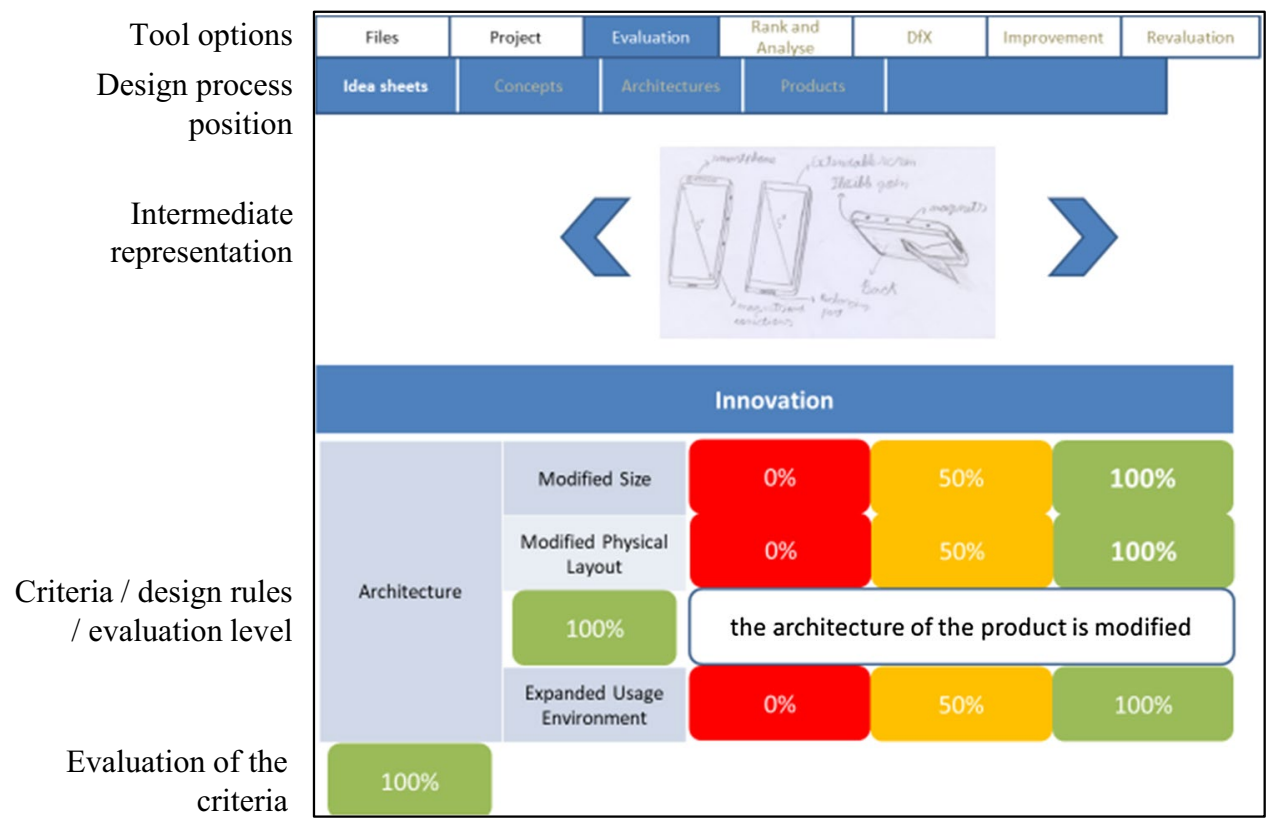

design project based on positioning in the design process and disciplines.

\section{References}

1. Anderson, D.M.: Design for Manufacturability: How to Use Concurrent Engineering to Rapidly Develop Low-Cost, High-Quality Products for Lean Production. CRC Press, Boca Raton (2014)

2. Contreras, A.M., Rosa, E., Pérez, M., Van Langenhove, H., Dewulf, J.: Comparative life cycle assessment of four alternatives for using by-products of cane sugar production. J. Clean. Prod. 17(8), 772-779 (2009)

3. Kellens, K., Dewulf, W., Overcash, M., Hauschild, M.Z., Duflou, J.R.: Methodology for systematic analysis and improvement of manufacturing unit process life cycle inventory (UPLCI) CO2PE! initiative (cooperative effort on process emissions in manufacturing). Part 2: case studies. Int. J. Life Cycle Assess. 17(2), 242-251 (2012)

4. Byggeth, S., Hochschorner, E.: Handling trade-offs in ecodesign tools for sustainable product development and procurement. J. Clean. Prod. 14(15-16), 1420-1430 (2006)

5. Liu, S., Leat, M., Smith, M.H.: State-of-the-art sustainability analysis methodologies for efficient decision support in green production operations. Int. J. Sustain. Eng. 4(3), 236-250 (2011)

6. Mantelet, F., Segonds, F., Jean, C.: Additive creativity: an innovative way to enhance manufacturing engineering education. Int. J. Eng. Educ. 34(6), 1776-1784 (2018)

7. Fischer, X., Nadeau, J.-P.: Research in Interactive Design. Virtual, Interactive and Integrated Product Design and Manufacturing for Industrial Innovation, vol. 3. Springer, Berlin (2011)

8. Shah, S.: Sources and Patterns of Innovation in a Consumer Products Field: Innovations in Sporting Equipment. Sloan School of Management, Massachusetts Institute of Technology, Cambridge (2000)

9. Zimmer, B., Yannou, B.: Proposal of a radical innovation project selection model based on proofs of value, innovation and concept.
In: Proceedings of DESIGN 2012, the 12th International Design Conference, Dubrovnik, Croatia, 2012

10. Carrillo-Hermosilla, J., del Río, P., Könnölä, T.: Diversity of ecoinnovations: reflections from selected case studies. J. Clean. Prod. 18(10-11), 1073-1083 (2010)

11. Segonds, F., Cohen, G., Véron, P., Peyceré, J.: PLM and early stages collaboration in interactive design, a case study in the glass industry. Int. J. Interact. Des. Manuf. IJIDeM 10(2), 95-104 (2016)

12. Howard, T.J., Culley, S.J., Dekoninck, E.: Describing the creative design process by the integration of engineering design and cognitive psychology literature. Des. Stud. 29(2), 160-180 (2008)

13. Neely, A., Gregory, M., Platts, K.: Performance measurement system design: a literature review and research agenda. Int. J. Oper. Prod. Manag. 15(4), 80-116 (1995)

14. Brezet, H.: Ecodesign, a Promising Approach to Sustainable Production and Consumption. United Nations Environment Programme UNEP, Paris (1997)

15. Chenhall, R.H.: Reliance on manufacturing performance measures, total quality management and organizational performance. Manag. Account. Res. 8(2), 187-206 (1997)

16. Saunders, M.N., Seepersad, C.C., Hölttä-Otto, K.: The characteristics of innovative, mechanical products. J. Mech. Des. 133(2), 1-9 (2011)

17. Garcia, R., Calantone, R.: A critical look at technological innovation typology and innovativeness terminology: a literature review. J. Prod. Innov. Manag. 19(2), 110-132 (2002)

18. Binz, M., Reichle, H.: Evaluation method to determine the success potential and the degree of innovation of technical product ideas and products. In: 35 Proceedings of ICED 05, 5th International Conference on Engineering Design, Melbourne, Australia, 15-18082005, 2005

19. Yannou, B., Zimmer, B., Farel, R., Jankovic, M., Stal Le Cardinal, J.: Proofs of Utility, Innovation, Profitability and Concept for Innovation Selection. ICED, Seoul (2013)

20. Jawahir, I.S., Dillon, O.W., Jr., Rouch, K.E., Josh, K.J., Venkatachalam, A., Jaafar, I.H.: Total life-cycle considerations in product design for sustainability: a framework for comprehensive evaluation, pp. 1-10 (2006) 
21. Tichem, M., Storm, T.: Designer support for product structuring-development of a DFX tool within the design coordination framework. Comput. Ind. 33(2), 155-163 (1997)

22. Luttropp, C., Lagerstedt, J.: EcoDesign and the ten golden rules: generic advice for merging environmental aspects into product development. J. Clean. Prod. 14(15-16), 1396-1408 (2006)

23. Cluzel, F., Yannou, B., Millet, D., Leroy, Y.: Eco-ideation and ecoselection of R\&D projects portfolio in complex systems industries. J. Clean. Prod. 112, 4329-4343 (2016)

24. O'Hare, J.A.: Eco-Innovation Tools for the Early Stages: An Industry-Based Investigation of Tool Customisation and Introduction. University of Bath, Bath (2010)

25. Bocken, N.M.P., Allwood, J.M., Willey, A.R., King, J.M.H.: Development of an eco-ideation tool to identify stepwise greenhouse gas emissions reduction options for consumer goods. J. Clean. Prod. 19(12), 1279-1287 (2011)

26. Hassan, M.F., Saman, M.Z.M., Sharif, S., Omar, B.: An integrated MA-AHP approach for selecting the highest sustainability index of a new product. Procedia Soc. Behav. Sci. 57, 236-242 (2012)

27. Halog, A., Schultmann, F., Rentz, O.: Using quality function deployment for technique selection for optimum environmental performance improvement. J. Clean. Prod. 9(5), 387-394 (2001)

28. Arena, M., Azzone, G., Conte, A.: A streamlined LCA framework to support early decision making in vehicle development. J. Clean. Prod. 41, 105-113 (2013)

29. Laverne, F., Segonds, F., D’Antonio, G., Le Coq, M.: Enriching design with $\mathrm{X}$ through tailored additive manufacturing knowledge: a methodological proposal. Int. J. Interact. Des. Manuf. IJIDeM 11(2), 279-288 (2017)

30. Rias, A.-L., Segonds, F., Bouchard, C., Abed, S.: Towards additive manufacturing of intermediate objects (AMIO) for concepts generation. Int. J. Interact. Des. Manuf. IJIDeM 11(2), 301-315 (2017)

31. Booth, J.W., Alperovich, J., Reid, T.N., Ramani, K.: The design for additive manufacturing worksheet. In: ASME 2016 International Design Engineering Technical Conferences and Computers and Information in Engineering Conference, 2016, pp. 1-8

32. Segonds, F.: Design by additive manufacturing: an application in aeronautics and defence. Virtual Phys. Prototyp. 13(4), 237-245 (2018)

33. Emmelmann, C., Herzog, D., Kranz, J.: 10—design for laser additive manufacturing. In: Brandt, M. (ed.) Laser Additive Manufacturing, pp. 259-279. Woodhead Publishing, Sawston (2017)

34. Ponche, R., Kerbrat, O., Mognol, P., Hascoet, J.-Y.: A novel methodology of design for additive manufacturing applied to additive laser manufacturing process. Robot. Comput. Integr. Manuf. 30(4), 389-398 (2014)
35. Laverne, F., Segonds, F., Anwer, N., Le Coq, M.: Assembly based methods to support product innovation in design for additive manufacturing: an exploratory case study. J. Mech. Des. 137, 1-8 (2015)

36. Brackett, D., Ashcroft, I., Hague, R.: Topology optimization for additive manufacturing. In: Proceedings of the Solid Freeform Fabrication Symposium, Austin, TX, 2011, pp. 348-362

37. Bovea, M.D., Pérez-Belis, V.: A taxonomy of ecodesign tools for integrating environmental requirements into the product design process. J. Clean. Prod. 20(1), 61-71 (2012)

38. Howarth, G., Hadfield, M.: A sustainable product design model. Mater. Des. 27(10), 1128-1133 (2006)

39. Cluzel, F.: Eco-Design Implementation for Complex Industrial System: From Scenario-Based LCA to the Definition of an EcoInnovative R\&D Projects Portfolio. Ecole Centrale Paris, Châtenay-Malabry (2012)

40. Le Bourhis, F.L., Kerbrat, O., Hascoet, J.-Y., Mognol, P.: Sustainable manufacturing: evaluation and modeling of environmental impacts in additive manufacturing. Int. J. Adv. Manuf. Technol. 69(9-12), 1927-1939 (2013)

41. Cheung, W.M., Marsh, R., Griffin, P.W., Newnes, L.B., Mileham, A.R., Lanham, J.D.: Towards cleaner production: a roadmap for predicting product end-of-life costs at early design concept. J. Clean. Prod. 87, 431-441 (2015)

42. Atzeni, E., Salmi, A.: Economics of additive manufacturing for end-usable metal parts. Int. J. Adv. Manuf. Technol. 62(9-12), 1147-1155 (2012)

43. De Benedetto, L., Klemeš, J.: The Environmental Performance Strategy Map: an integrated LCA approach to support the strategic decision-making process. J. Clean. Prod. 17(10), 900-906 (2009)

44. Jasch, C.: Environmental performance evaluation and indicators. J. Clean. Prod. 8(1), 79-88 (2000)

45. Borgianni, Y., Cascini, G., Pucillo, F., Rotini, F.: Supporting product design by anticipating the success chances of new value profiles. Comput. Ind. 64(4), 421-435 (2013)

46. Budde, L., Nagler, O., Friedli, T.: A method to set up a complexity index to improve decision-making performance. Procedia CIRP 36, 53-58 (2015)

47. Campbell, R.I., Jee, H., Kim, Y.S.: Adding product value through additive manufacturing. In: Lindeman, U. et al (eds.) ICED 13: 19th International Conference on Engineering Design, Proceedings Volume DS 75-4, Design for Harmonies, vol 4, pp. 259-268. Product, Service and Systems Design, Seoul, Korea (2013) 